\title{
Judicialização da saúde: aspectos legais e impactos orçamentários
}

\author{
The judicialisation of health: legal aspects and budgetary impacts
}

\section{Ivan Corrêa LEITE* Paulo Roberto Haidamus de Oliveira BASTOS ${ }^{* *}$}

\begin{abstract}
Resumo: O presente artigo visa analisar a judicialização da saúde com foco nas decisões judiciais concessivas de medicamentos no Estado de Mato Grosso do Sul, haja vista esta apresentar-se como um fenômeno atual de larga abrangência quanto ao número de decisões judiciais, ao montante despendido para o cumprimento de tais decisões e as implicações orçamentárias do setor da saúde. Busca-se questionar se tais decisões, ao deixarem de considerar a escassez de recursos orçamentários, não geram prejuízos à efetividade das políticas públicas de saúde, comprometendo os princípios norteadores do SUS. Foi utilizado de pesquisa bibliográfica, bem como de dados do Tribunal de Justiça de Mato Grosso do Sul. Dentre as conclusões apresentadas tem-se que a judicialização da saúde acaba por gerar reflexos que abalam a condução administrativo-financeira do Estado.

Palavras-chave: Judicialização. Recursos Orçamentários. Saúde.
\end{abstract}

\begin{abstract}
This article analyses the judicialisation of health with a focus on the judicial decisions licencing medicines in the State of Mato Grosso do Sul, as this is a widespread phenomenon in terms of the number of judicial decisions, the amount spent to comply with such decisions and the budgetary implications to the health sector. It questions whether these decisions, when they fail to consider the scarcity of budgetary resources, generate damage to the effectiveness of public health policies, compromising the guiding principles of SUS (Single Health System). Bibliographical research has been used, as well as data from the Court of Mato Grosso do Sul. Among the conclusions presented is that the judicialisation of health ends up generating responses that undermine the administrative and financial conduct of the State.
\end{abstract}

Keywords: Judicialisation. Budget resources. Health.

Submetido em: 12/1/2018. Aceito em: 17/2/2018.

\section{INTRODUÇÃO}

presente artigo analisa e investiga o contexto e a implicação das decisões judiciais que vêm concedendo medicamentos, focando apenas nos usuários do Sistema Único de Saúde (SUS), tendo por base o estado de Mato Grosso do Sul, utilizando-se exclusivamente de dados secundários de domínio público e da literatura pertinente. Tais dados foram acessados através do Comitê Estadual de Saúde/Núcleo de Apoio Téc-

\footnotetext{
* Advogado. Doutorando no Programa de Pós-Graduação em Saúde e Desenvolvimento na Região CentroOeste da Universidade Federal de Mato Grosso do Sul (UFMS, Campo Grande, Brasil). Professor do Curso de Graduação da Faculdade de Direito da Universidade Federal de Mato Grosso do Sul. (UFMS, Campo Grande, Brasil). Av. Costa e Silva, s/nº, Cidade Universitária, Campo Grande (MS), CEP.: 79070-900. E-mail: <ivancorrealeite16@gmail.com>. ORC ID: <https://orcid.org/oooo-0oo3-2967-5629>.

${ }_{* *}^{*}$ Educador. Doutor em Educação pela Pontifícia Universidade Católica de São Paulo. Pesquisador Sênior do Programa de Pós-Graduação em Saúde e Desenvolvimento na Região Centro-Oeste da Universidade Federal de Mato Grosso do Sul (UFMS, Campo Grande, Brasil). Av. Costa e Silva, s/no , Cidade Universitária, Campo Grande (MS), CEP.: 79070-900. E-mail: <phaidamus43@gmail.com>. ORC ID: <https://orcid.org/oooo0002-8885-1461>.
} 
nico (NAT), disponíveis no sítio do Tribunal de Justiça do estado de Mato Grosso do Sul (TRIBUNAL DE JUSTIÇA, 2017).

Primeiramente, necessário se faz conceituar o termo judicialização da saúde ou judicialização da medicina. Para Sant'ana et al. (2011), trata-se de um evento sociojurídico que se manifesta notadamente nos processos judiciais que visam a concessão de medicamentos.

O fenômeno da judicialização tem gerado efeitos em todos os entes federativos, considerando que o número de ações judiciais sobre o tema obteve um crescimento relevante. Nesta linha, os dados do Conselho Nacional de Justiça (CNJ) apontam que em 2016 o número de ações judiciais sobre o tema ascendia a de um milhão e trezentos mil processos (CONSELHO NACIONAL DE JUSTIÇA, 2017).

O crescimento do número de processos judicias implicou diretamente no dispêndio dos entes públicos para o cumprimento das decisões judiciais determinando o fornecimento de medicamentos. Segundo dados disponibilizados pelo Tribunal de Contas da União (TCU), abrangendo União, Estados e municípios, verificou-se que os gastos da União com processos judiciais referentes à saúde em 2015 foram de R\$ 1 bilhão, significando um aumento de mais de $1.300 \%$ (de R 70 milhões para R\$ 1 bilhão) em sete anos. Ainda segundo os dados do TCU, o fornecimento de medicamentos, alguns sem registro no Sistema Único de Saúde, correspondia a $80 \%$ das ações ${ }^{1}$.

Estes dados constam da auditoria realizada pelo TCU, abrangendo a União, as secretarias de saúde de alguns municípios, além do judiciário dos Estados de Minas Gerais e Rio Grande do Sul.

Em Mato Grosso do Sul, o panorama de crescimento do número de ações não se altera, tendo havido um crescimento de 79\% no volume de ações de saúde em 2016 em relação a 2015, sendo observado que, quando analisado o pedido de medicamentos, o crescimento sobe para $102 \%$ no mesmo período. Ou seja, deste volume, mais de 50\% referiam-se a medicamentos.

\begin{tabular}{|c|c|c|c|}
\hline \multicolumn{4}{|c|}{ Relatório de Processos - Classificação por pedidos da área de saúde } \\
\hline Pedidos & $\begin{array}{c}\text { Quantidade de pro- } \\
\text { cessos em 2015 }\end{array}$ & $\begin{array}{c}\text { Quantidade de proces- } \\
\text { sos em 2016 }\end{array}$ & Aumento percentual \% \\
\hline Medicamentos & 1706 & 3449 & $102,16 \%$ \\
\hline Total geral de pedidos & 3233 & 5795 & $79,24 \%$ \\
\hline
\end{tabular}

Fonte: Tribunal de Justiça ([2017]).

A relevante quantidade de processos judiciais fez com que o Conselho Nacional de Justiça criasse, por meio da Portaria no 650/2009 (CONSELHO NACIONAL DE JUSTIÇA, 2009), um Grupo de Trabalho para estudo e proposta sobre medidas a serem tomadas nos casos de judicialização.

${ }_{1}^{1}$ Acórdão 1787/2017 TCU - Plenário - Processo 009.253/2015-7. 
Atente-se que, embora o fenômeno da judicialização possua caráter nacional, é preciso que se analise as questões inerentes a cada um dos estados da federação, tais como, a sua população, a sua densidade demográfica, o grau de estruturação do seu sistema de saúde e as condições econômicas do estado, vez que estas implicam diretamente nos recursos direcionados ao setor saúde.

O Mato Grosso do Sul apresenta situações peculiares, uma vez que possui fronteira com dois países e, em sua maior parte, sem qualquer obstáculo natural, possibilitando a livre circulação de pessoas. O estado possui cidades-gêmeas nacionais: Bela Vista, que é vizinha de Bella Vista Norte (Paraguai); Corumbá, que está ao lado de Puerto Quijarro (Bolívia); Mundo Novo, que tem como vizinha Salto del Guairá (Paraguai); Paranhos, com Ypejhú (Paraguai) após a fronteira; Porto Murtinho, que é vizinha de Capitán Carmelo Peralta (Paraguai); e, Ponta Porã, que fica ao lado de Pedro Juan Caballero (Paraguai).

Tal fato importa em uma relevante busca de atendimento por estrangeiros no SUS que varia conforme a região, tipo de fronteira e país fronteiriço. Nas fronteiras do Mato Grosso do Sul com Paraguai e Bolívia, a demanda de brasileiros não residentes é mais intensa, assim como a demanda dos estrangeiros habitantes de região transfronteiriça, considerando que o SUS possui característica de universalidade, sendo esta demanda considerada frequente ou muito frequente em 80\% a 90\% dos municípios pesquisados (GIOVANELLA et al., 2007).

Esta situação acaba por provocar um aumento significativo da demanda por ações de saúde no Mato Grosso do Sul, entre estas o fornecimento de remédios, mormente nas cidades gêmeas e nas regiões de fronteiras (RIBAS et al., 2013).

\section{DISPOSIÇÕES NORMATIVAS DO DIREITO À SAÚDE}

Anote-se que a base constitucional e infraconstitucional referente ao direito à saúde, encontra-se estabelecida no art. 196 da CF/88 (BRASIL, 1988), uma vez que a saúde é direito de todos e dever do Estado, garantido mediante políticas sociais e econômicas que visem à redução do risco de doenças.

Considerando que a República Federativa do Brasil constitui-se em Estado Democrático de Direito, o qual deve respeito às normas constitucionais, e, levando-se em conta que as políticas públicas devem ser implementadas a fim de minimizar as desigualdades sociais, resta claro que tais políticas públicas são implementadas visando resguardar a eficácia dos direitos fundamentais.

Portanto, tais direitos apresentam-se como aqueles, cujo objetivo é a garantia de condições mínimas para o bem-estar social, atendendo as necessidades dos direitos dos cidadãos, desta forma, indivíduos. Por este motivo, ou seja, considerando que os direitos sociais devem atender as necessidades da sociedade, é imprescindível ter em mente o imperativo da ação de alguém ou algo, para que estes interesses se concretizem. Por este motivo, em que pese a realização dos direitos sociais, estes são concretizados a partir da ação do Estado, e assim considera-se a necessidade peremptória de sua intervenção na ordem social para viabilização da justiça distributiva. 
Os direitos fundamentais estão previstos na ordem constitucional com o caráter de norma de aplicação imediata. Dessa forma, leva-se em consideração a importância da Constituição que "[...] é entendida como um procedimento político justo que incorpora as iguais liberdades políticas e procura assegurar o seu justo valor de modo que os processos de decisão política sejam acessíveis a todos numa base aproximadamente igual [...]" (CANOTILHO, 2003, p. 1.387). Por conseguinte, o direito à saúde encontra-se garantido pela Constituição Federal, sendo este um direito de todos na conformidade do disposto nos artigos 6o e 196 (BRASIL, 1988).

Tais normas possuem caráter programático atinente a todos os entes políticoadministrativos, onde estes não podem furtar-se da responsabilidade de oportunizar a todos os cidadãos os recursos essenciais ao gozo do direito à saúde, o que implica em imposição solidária ao seu cumprimento no caso de indisponibilização pelo poder público de determinado meio vital à sobrevivência do indivíduo.

Portanto, a saúde revela-se como um direito público subjetivo protegido pelo texto constitucional, cabendo ao Estado planejar, desenvolver e efetivar políticas públicas de caráter socioeconômico com a finalidade de assegurar a todos os cidadãos o acesso universal e igualitário à assistência médico-hospitalar, realçando que a questão do fornecimento de medicamentos também se encontra albergada no âmbito do direito à saúde.

Tal preceito é complementado pela Lei no 8.080/90 (BRASIL, 1990), em seu artigo 2º, onde ressalta que a saúde é um direito fundamental do ser humano, devendo o Estado prover as condições indispensáveis ao seu pleno exercício.

Nesta linha de raciocínio, têm-se concomitantemente normas de caráter constitucional e infraconstitucional determinando que a responsabilidade referente às ações e serviços de saúde abrange o Estado, englobando, portanto, tanto à União, quanto os Estados, Distrito Federal e os Municípios, na conformidade do que dispõe o art. 23, II da Constituição Federal de 1988 (BRASIL, 1988). Assim, cabe a todos os entes federativos efetivar a garanta do direito à saúde no que concerne à sua competência administrativa.

Este direito, face à sua relevância, faz com que o Estado tome para si a obrigatoriedade pela prevenção, tratamento e controle de doenças, o que se operacionaliza por meio de políticas de saúde que propiciem condições de estruturação de um sistema que garanta o real e efetivo acesso aos serviços de saúde. Observe-se que a Constituição em vigor dispõe de forma expressa a saúde como um direito social do cidadão, portanto direitos estes que são deveres do Estado.

Para Silva (2009), os direitos sociais são direitos fundamentais que possuem uma característica prestacional, sendo direitos chamados de segunda geração, portanto, com seu universo de atuação na forma de uma ação e não de omissão, visando efetivar condições de vida aos cidadãos com maior necessidade, bem como reestabelecer a igualdade em face de situações sociais desiguais.

Sarlet (2001), aludindo sobre a questão concernente aos direitos fundamentais e direitos sociais, informa que "[...] os direitos sociais prestacionais têm por objeto conduta positiva do Estado

Argum., Vitória, v. 10, n. 1, p. 102-117, jan./abr. 2018. 
(ou particulares destinatários da norma), consistente numa prestação de natureza fática [...]" (SARLET, 2001, p. 261).

Há de se constar, face as normas constitucionais e infraconstitucionais supracitadas, as leis, regras e princípios que regem o sistema sanitário do Brasil, uma vez que confirmam a ideia de que a saúde apresenta-se como direito fundamental e as políticas públicas de saúde são o meio primeiro de efetivação deste direito.

Dessa forma, o Estado deve responder pelo seu papel de criar opções para a garantia das necessidades sociais onde se fizer relevante, por conseguinte, deve zelar e efetivar a proteção dos direitos constitucionais, não podendo isentar-se da integração das lacunas tendentes a impedir ou dificultar a proteção dos direitos fundamentais (SILVA, 2007).

\section{DO FINANCIAMENTO DA SAÚDE}

Consoante se verifica do art. 198 da Constituição Federal (BRASIL, 1988), há a fixação das diretrizes para a organização da saúde, na qual determina que as ações e serviços públicos de saúde devem integrar uma rede regionalizada e hierarquizada, constituindo um sistema único, sustentado com recursos do orçamento da seguridade social, da União, dos Estados, do Distrito Federal e dos Municípios.

Nesse diapasão, a implantação do SUS sob o aspecto de gestão tripartite, infere-se na politica cooperativa entre os entes federados. Dessa forma, o art. 23, II, da Carta Magna, colocou incumbência da saúde e da assistência pública dentro da competência comum da União, dos Estados, do Distrito Federal e dos Municípios. Por sua vez, o art. 24, XII, da Constituição Federal, atribui competência à União, aos Estados e ao Distrito Federal legislar concorrentemente sobre a defesa da saúde. E, por fim, em seu art. 30, VII, confere aos Municípios o dever de prestar, com cooperação técnica e financeira da União e dos Estados, serviços e atendimento à saúde da população.

Adiante, concernente às fontes de custeio, o orçamento da seguridade social destina ao SUS, segundo a receita estimada, os recursos necessários à realização de suas finalidades, em conformidade com os parâmetros da Lei de Diretrizes Orçamentárias, consoante se verifica do art. 31, da Lei no 8.08o/90 (BRASIL, 1990).

Ao regulamentar o $§ 3^{0}$ do art. 198 da Constituição Federal, a LC no 141/12, fixou os valores mínimos a serem aplicados anualmente pela União, Estados-membros, Distrito Federal e Municípios em ações e serviços públicos de saúde, além de estabelecer critérios de rateio dos recursos de transferências para a saúde, assim como as normas de fiscalização, avaliação e controle das despesas com saúde nas três esferas de governo.

Nesse sentido, o percentual mínimo é de $12 \%$ para os Estados e de $15 \%$ para os Municípios. Quanto à União, impende ressaltar que, com a promulgação da Emenda Constitucional no 86/2015 (BRASIL, 2015), alterando o $§ 2^{\text {o }}$ do art. 198 da Constituição Federal, impôs-se à União gastos mínimos em saúde considerando a Receita Corrente Líquida (RCL), sendo de 13,2\% em 2016, com evolução anual progressiva até atingir 15\% da RCL no ano de 2020. Certamente, o que se verifica é o clarividente subfinanciamento da saúde, fazendo com que os Muni- 
cípios sejam os principais sacrificados, haja vista que despendem em torno de $23 \%$ da sua receita líquida com ações e serviços de saúde, enquanto que os Estados-membros dificilmente ultrapassam a margem de $14 \%$. A estimativa dos analistas é de que os novos percentuais fixados pela Emenda Constitucional no 86/2015, reduzirão os gastos da União com saúde no ano de 2016 em aproximadamente nove bilhões de reais (US\$ 2,3 bilhões), considerando o que deveria ser despendido se fossem mantidos os critérios previstos na Lei Complementar no 141/2012. Esse fato preocupa os envolvidos com o direito à saúde, porque deverá haver uma maior desassistência, e, por conseguinte, o aumento na judicialização (DRESCH, 2016).

Dessa forma, a fim de amenizar a defasagem de investimentos, verifica-se a necessidade de aumentar o financiamento da saúde, atentando-se que tal medida, por si só, não resolverá os problemas de ineficiência dos serviços, haja vista ser exigido também a melhora da gestão (DRESCH, 2016).

Sendo assim, alinhavados com tais premissas, o Poder Judiciário não pode ignorar as diretrizes administrativas e regulatórias da saúde, ao contrário, suas decisões não podem gerar desequilíbrio orçamentário, haja vista existir no SUS uma estrutura administrativa hierarquizada.

\section{A JUDICIALIZAÇÃO DA SAÚDE E A RESPONSABILIDADE DOS ENTES FEDERATI- VOS}

Sendo, portanto, a saúde um direito fundamental, há que se definir o conceito de saúde a ser fornecido pelo Estado que envolve uma gama de ações, dentre estas o fornecimento de remédios que visam a prevenção, recuperação e tratamento de doenças.

Nesta linha de pensamento, uma vez reconhecido que o direito à saúde é um direito básico do cidadão e fundamento do Estado Democrático de Direito, não se poderia negar ao cidadão o fornecimento dos serviços de saúde, dentre estes os fármacos, caso em que, havendo negativa de fornecimento ao cidadão, tem este o direito de socorrer-se ao Poder Judiciário a fim de corrigir tal recusa.

Entretanto, importa considerar que o art. $2^{\circ}$ da Constituição Federal (BRASIL, 1988) consagra o princípio da separação dos poderes no que concerne as competências e funções de cada um, tendo por corolário o princípio da especialidade. Não se trata, porém, de divisão de poderes, mas sim de distribuições relativas às funções de cada um dos poderes em relação às funções estatais básicas. Assim, de forma sintética, a função executiva seria exercida pelo Poder Executivo, por sua vez, a função legislativa seria efetuada pelo Poder Legislativo, e, por fim, a função jurisdicional ficaria a cargo do Poder Judiciário.

Portanto, é possível identificar três funções típicas distintas, cada uma delas de competência de um dos poderes: quanto ao legislativo, face a sua função legiferante, cabe a edição de normas de caráter geral; por sua vez, ao executivo compete a aplicação das normas editadas no caso concreto, respeitando os princípios da administração pública, calcados no art. 37 da Constituição Federal (BRASIL, 1988); e, finalmente, cumpre ao judiciário a solução de conflitos, interpretando e aplicando as normas postas a casos concretos (judiciais).

Argum., Vitória, v. 10, n. 1, p. 102-117, jan./abr. 2018. 
Na realidade, tem-se que não há propriamente uma divisão, mas sim, a repartição das funções estatais básicas que são atribuídos a órgãos independentes e especializados. Caracteriza-se na divisão funcional do poder político do Estado em que cada função estatal básica seria atribuída a um órgão especializado, recebendo a denominação de acordo com a destinação que lhe compete.

Desta forma, caberia ao legislativo e ao executivo formularem políticas públicas para a efetivação dos direitos sociais elencados no art. 6o do texto constitucional.

Adiante, verifica-se um tensionamento entre o judiciário e os demais poderes, no que concerne ao fenômeno da judicialização, que assume contornos mais graves quando o sistema se depara com decisões do Poder Judiciário (brasileiro) tidas como invasoras de subsistemas ou epitetadas como típicas decisões que "judicializam a política”, como é o caso de sentenças emanadas pelos juízes e tribunais brasileiros determinando a inclusão/criação de vagas em escolas públicas, fornecimento de remédios com fundamento no art. 196 da Constituição (STRECK, 2004).

Em sentido diverso posiciona-se Barroso (2009), haja vista que a judicialização significa que algumas questões de larga repercussão política ou social estão sendo decididas por órgãos do Poder Judiciário, e não pelas instâncias políticas tradicionais: o executivo e o legislativo. Portanto, envolve uma transferência de poder para juízes e tribunais, com alterações significativas na linguagem, na argumentação e no modo de participação da sociedade.

Devido a sua grande relevância para a temática, há que se ressaltar a ocorrência de três fatos de grande importância atinentes à questão da judicialização da saúde, a saber: a) a realização da Audiência Pública no 4, nos meses de abril e maio de 2009; b) a edição pelo CNJ, em 2010, da Recomendação n. 31 (CONSELHO NACIONAL DE JUSTIÇA, 2010), que versa sobre a orientação aos tribunais para utilizar-se de mecanismos, no intuito a dar subsídios aos magistrados nos julgamentos das questões relacionadas à judicialização da saúde; e, c) a Lei no 12.401, de 28 de abril 2011, que trata da assistência terapêutica integral no SUS (BRASIL, 2011).

Ao se analisar a Recomendação no 31 do CNJ, deve-se ter em conta a existência de estudos nos quais apontam que uma fração considerável dos magistrados brasileiros, ao fundamentar suas decisões, consideram o direito à saúde de forma individual e não coletivamente; interpretam o direito à saúde e os princípios do SUS como direito de qualquer cidadão relacionado à saúde; ignoram o fato de que a concretização do direito à saúde envolve gastos públicos vultosos; e, não levam em consideração as políticas de distribuição de medicamentos já existentes (TERRAZAS, 2014).

Observe-se que, no intuito de dar efetividade ao disposto na norma constitucional, institucionalizou-se o Sistema Único de Saúde (SUS), através da Lei no 8.08o/1990, regulamentada em 2011 pelo Decreto no 7.508/11 (BRASIL, 2011). Adiante, com o objetivo de garantia da eficácia e segurança dos medicamentos a serem distribuídos pelo SUS, a portaria MS no 3.916/98 (BRASIL, 1998) estabeleceu a política nacional de medicamentos. Em maio de 2004, tendo por objetivo a promoção, proteção, recuperação da saúde, medicamento como insumo essencial, estabeleceu-se a política nacional de assistência farmacêutica (PNAF), por meio da Resolução no 338 do CNS (CONSELHO NACIONAL DE SAÚDE, 2004).

Argum., Vitória, v. 10, n. 1, p. 102-117, jan./abr. 2018. 
O termo medicamentos essenciais foi conceituado pela Organização Mundial de Saúde (OMS) como sendo aqueles que satisfazem as necessidades de atenção à saúde da maioria da população (WORLD HEALTH ORGANIZATION, 1997), observando o seu uso racional, além de propiciar economia, considerando que os medicamentos selecionados devem ser aqueles com eficácia e segurança comprovadas, ao melhor custo possível.

Tendo em vista a aceitação mundial do conceito de remédios essenciais, este permite aos gestores de saúde a elaboração de uma política pública que abrange a promoção e racionalização da compra e a distribuição de medicamentos, possibilitando ainda, além da redução do gasto orçamentário, efetivar uma maior programação na aquisição e estoque, tendo ênfase nos aspectos relativos à qualidade dos fármacos.

Reitera-se que o fenômeno da judicialização gerou um aumento exponencial do número de ações requerendo ao poder judiciário à concessão de fármacos. Tal fenômeno vem provocando debates e reflexões, muitas vezes antagônicas; nos campos da bioética, das ciências da saúde, do direito e da economia, além de uma verdadeira frustração dos gestores públicos responsáveis pelo planejamento e execução de programas de saúde, vez que o exacerbado número de determinações judiciais para a concessão de remédios acaba por resultar em relevantes impactos financeiros à União, aos estados e aos municípios, em prejuízo das políticas de saúde já previamente planejadas e instituídas que visam a atender toda a coletividade (MENDES, 2009).

Assim, frente às disposições constitucionais impositivas no tocante à saúde como dever do Estado, a responsabilidade é de todos os entes federados, bem como, o acesso à saúde deve ser efetivado por meio de políticas públicas de caráter socioeconômico, observando-se o desenvolvimento das ciências da saúde no intuito de prevenção, recuperação e tratamento de doenças. Tem-se como prioritárias as ações preventivas, na forma como dispõe o art. 298, II da Constituição brasileira (CRUZ, 2014).

Para Barroso (2008), as decisões concessivas de medicamentos sem uma efetiva observação criteriosa da demanda podem redundar em efeitos negativos para todo o sistema de saúde pública, ou seja, acaba por causar uma disfunção em todo o sistema.

Nesta mesma linha, o risco de se desenvolver a via judicial como principal meio para se garantir o acesso ao medicamento acaba por gerar danos relevantes do direito à saúde, atentando contra os princípios éticos e legais, notadamente ao do acesso igualitário à saúde (BAPTISTA; MACHADO; LIMA, 2009).

Porém, cabe observar que a função típica do executivo é a promoção e execução de políticas públicas que destinam-se a vários setores da administração pública, sendo a saúde um destes.

Assim, se por um lado reconhece-se o direito à saúde, constitucionalmente garantida a todos os usuários do SUS, sejam estes brasileiros ou não, em contrapartida exige-se da coletividade que dê sua contribuição para o funcionamento e manutenção do sistema. Tal contribuição pode assumir a forma de recursos que derivam da arrecadação tributária, ou ainda, por meio de ações positivas, através da exigência de direitos, bem como a participação da coletividade 
para o aprimoramento, e, por fim, em ações negativas, com a abstenção de condutas que venham a prejudicar a saúde como um todo (NUNES, 2009).

Ferreira Filho (2003) alude que há uma extrapolação das atribuições e competências do judiciário no tocante às políticas públicas de saúde de competência do executivo e do legislativo, gerando o que se denominou de "[...] aristocracia togada" (FERREIRA FILHO, 2003, p. 216).

Para Mattos e Souza (2011), a judicialização apresenta-se como uma transferência de poder para as instituições judiciais em detrimento das instâncias políticas tradicionais, que são o Legislativo e o Executivo, observando-se que tal situação mostra-se como a ingerência de um poder (judiciário) em outros (executivo/legislativo).

Vários autores que têm estudado a questão da judicialização posicionam-se na vertente de que o fato de ser determinado ao Estado o fornecimento de certo medicamento e ou insumo, deve ser observado também sobre a ótica da ciência da saúde, vez que para ter acesso ao tratamento é preciso observar os protocolos clínicos e as diretrizes terapêuticas, nos termos do que dispõe a Lei no 8.08o/9o em seu capítulo sobre a assistência terapêutica e a incorporação de tecnologia em saúde, incluído recentemente pela Lei no $12.401 / 11$ e pelo Decreto $n^{-}$ 7.508/11 (MACHADO et al., 2011; VIEIRA; ZUCCHI, 2007; WANG; FERRAZ, 2013).

Portanto, para o efetivo cumprimento do direito à saúde faz-se necessário a formulação de políticas públicas que levem em consideração vários fatores, e norteadas pelos princípios do direito à saúde: a equidade e a universalidade. Observe-se que tais políticas são operadas por intermédio de um sistema de saúde, criado pelas diversas entidades estatais, e ordenado por diferentes elementos setoriais e programáticos, que possuem a disposição organizada e integrada dos serviços tendentes aos cuidados das doenças e na promoção da saúde latu sensu (MATTOS; SOUZA, 2011).

Uma vez estabelecidas as políticas para o setor, estrutura-se um sistema de saúde que consuma as ações de saúde com base em um planejamento logístico que visa a obtenção da máxima eficiência, atingimento dos objetivos estabelecidos, bem como de sua efetividade das ações de saúde (TAMAKI; TANAKA, 2012).

No entanto, a negação desta obrigação teria como consequência a renúncia do reconhecimento da qualidade de verdadeiros direitos. A ineficácia do Estado em promover os serviços sociais básicos não está na falta de leis que os regulamente, mas sim na formulação, implementação e manutenção de políticas públicas. Tais políticas devem considerar o direito à saúde discernindo-os em dois planos diferentes os individuais e coletivos (TRAVASSOS, 2012).

Em relação ao plano individual pode-se citar a liberdade de escolha da pessoa entre as modalidades possíveis de tratamento, contudo, sem olvidar o direito do profissional de saúde sobre a aplicação ou não de determinado tratamento, cabendo a este a alternativa de escolha entre os existentes, vez que seus conhecimentos técnicos o habilitam a tal. No que tange ao plano social, o direito à saúde pode ser avaliado da seguinte forma: as obrigações dos indivíduos em virtude das necessidades coletivas, como por exemplo, as que são dotadas com o objetivo de controle de doenças infectocontagiosas (vacinação e isolamento). Por outro lado,

Argum., Vitória, v. 10, n. 1, p. 102-117, jan./abr. 2018. 
o Estado deve garantir a oferta de cuidados de saúde, para quem deles necessitam (NOGUEIRA; PIRES, 2004).

Há quem defenda que a Constituição estatuiu, quanto aos direitos sociais, normas de conteúdo meramente programático, ou seja, uma norma de eficácia limitada, que não produz plenamente seus efeitos até que haja a implementação por lei infraconstitucional das políticas públicas a serem adotadas (FERRAZ; WANG, 2014).

Portanto, para o efetivo cumprimento do direito à saúde faz-se necessário a formulação de políticas públicas que levem em consideração vários fatores: questões estratégicas, políticas, econômicas, circunstanciais (oportunidades), enfim, os diversos aspectos que afetam a gestão de um serviço (TAMAKI; TANAKA, 2012).

Segundo a disposição da Lei no 8.o8o/9o, cabe aos estados e municípios a responsabilidade de elaborar o planejamento de saúde que será a base para os procedimentos no seu âmbito administrativo (BERRETA; LACERDA; CALVO, 2011), assim o planejamento das ações de saúde impõe-se como base para a tomada de decisão dos procedimentos a serem estabelecidos pelo ente estatal no intuito de assegurar ao cidadão o seu direito à saúde.

Registre-se que, tanto a norma constitucional, como a infraconstitucional convergem no sentido que, a real eficácia do direito à saúde encontra-se na dependência de planejamento de ações e serviços de saúde que necessitam de prestações materiais para sua efetivação, ou seja, a eficácia de tais prestações, em última análise, depende de recursos públicos disponíveis. A obrigação do Estado de prover diretamente uma prestação a cada pessoa necessitada não é posição pacífica na jurisprudência nem na doutrina, portanto em relação à questão orçamentária, a constatação da falta de recursos faz com que os gestores públicos responsáveis pelo setor se posicionem no entendimento que não há possibilidade fática do atendimento das necessidades e anseios de todos os usuários (TRAVASSOS, et al., 2013).

Na definição constante da Lei no 8.08o/9o, o SUS foi configurado como “[...] o conjunto de ações e serviços de saúde, prestado por órgãos e instituições públicas federais, estaduais e municipais da Administração Direta e Indireta [...]" (BRASIL, 1990, não paginado), e estruturado com base nos critérios de universalidade, descentralização, integralidade, equidade e controle e participação social.

Quanto à universalidade, significa dizer que ao SUS compete atender a toda a população, independentemente de suas condições pessoais (nacionalidade, naturalidade, classe social etc.), ser beneficiado pelas ações que programam políticas públicas direcionadas à saúde da população e ter à sua disposição todos os medicamentos e insumos indispensáveis para prevenção e proteção de sua saúde, seja através dos serviços estatais ou privados conveniados ou contratados pelo poder público (MAPELLI JÚNIOR et al., 2012; VIANA; DAL POZ, 2005).

No que tange à descentralização, atenta-se para a possibilidade de criação de uma gestão local que abarca a participação de todos os atores envolvidos, sejam trabalhadores, prestadores de serviços, gestores e usuários. Ou seja, apresenta-se um novo formato organizativo para os serviços sob a lógica da integralidade, da regionalização e da hierarquização (VIANA, 2005). 
Adiante, a integralidade alcança além dos parâmetros dos serviços de saúde que têm como base a assistência médica individual curativa, uma vez que as ações de saúde devem ser combinadas e voltadas a atender o indivíduo como um ser humano integral. Por sua vez, o acesso igualitário abrange o fato de que todo cidadão deverá ser atendido conforme suas necessidades, fazendo com que os serviços de saúde considerem que em cada população existem grupos que vivem de forma diferente, têm problemas e modos de adoecer específicos, necessitando assim de oportunidades diferenciadas (VICENTINI, 2007).

A Lei no 8.08o/9o (BRASIL, 1990) institui a alocação de recursos a serem estabelecidos que devem levar em conta o estabelecimento de prioridades de padrões epidemiológicos, sendo que tais padrões são melhores identificados pelos gestores municipais e estaduais, ou seja, um caráter de descentralização, vez que os padrões epidemiológicos variam entre os municípios e estados da União.

Nesta situação, cada um dos gestores possui em seu planejamento um montante de recursos alocados para a execução dos serviços de saúde, na conformidade com as normas orçamentárias determinadas em várias leis (MATTOS; SOUZA, 2011). O grande problema atual é que o judiciário, face às suas decisões, adentra a questões que, em tese, seriam pertinentes ao executivo na qualidade de gestor do sistema, por meio de políticas públicas que dependem em última análise de recursos para sua implementação.

Assim, em última análise, há que se constatar o fato que para se dar efetividade ao direito à saúde, a própria norma constitucional determina a formulação de políticas públicas, políticas estas que para sua implementação encontram-se na dependência de recursos orçamentários alocados. Tem-se que, com o aumento considerável das decisões judiciais que concedem medicamentos, os recursos orçamentários já escassos necessitem serem realocados de outras rubricas do setor de saúde ou mesmo dos outros setores também dispostos nos direitos sociais constantes do art. 6o da Constituição Federal de 1988.

\section{CONSIDERAÇÕES FINAIS}

Partindo-se da premissa que a judicialização é considerada um fenômeno multifacetário, vez que repercute não só no direito, mas também em vários campos da ciência, observa-se que o art. 6o da Constituição Federal de 1988 dispõe que tanto a saúde, como outros direitos, fazem parte do rol de direitos sociais. No mesmo sentido, o art. 196 estabelece que a saúde é um dever de todos e dever do Estado, garantido mediante políticas sociais e econômicas que visem à redução de risco de doenças e de outros agravos e ao acesso universal e igualitário às ações de saúde para sua proteção, proteção e recuperação.

De plano mostra-se inconteste a disposição no texto constitucional da adoção de políticas sociais e econômicas, portanto, não se pode olvidar da necessidade de se considerar fatores econômicos para o efetivo cumprimento do direito à saúde.

Nesta mesma linha, o art. 197 dispõe que cabe ao Poder Público a regulamentação, a fiscalização e o controle das ações de saúde, função de competência dos poderes executivo e legislativo. 
Considerando o aumento expressivo do número de decisões judiciais que determinam ao executivo, gestor do sistema de saúde, a concessão de medicamentos, muitos deles de alto custo, ou até mesmo sem o competente registro na Anvisa, tal fato acaba por comprometer as políticas sociais e econômicas, uma vez que induzem a realocação de recursos orçamentários já escassos.

As decisões judicias concessivas de medicamentos redundam em uma disfunção na organização das políticas administrativas do setor de saúde, considerando que o fenômeno da judicialização gera um impacto relevante no orçamento público brasileiro como um todo, passando assim ao poder judiciário a função de efetivar as políticas públicas. Porém, tal ingerência provoca uma política de coerência questionável e inapropriada a nível social global, uma vez que acabam por gerar reflexos que abalam a condução administrativo-financeira do Estado, sob o risco de grande instabilidade para a consecução de serviços básicos outrora estáveis.

\section{REFERÊNCIAS}

BAPTISTA, T.W.F.; MACHADO, C.V.; LIMA, L. D. Responsabilidade do Estado e direito à saúde no Brasil: um balanço da atuação dos Poderes. Ciência \& Saúde Coletiva, Rio de Janeiro, v. 14, n. 3, p. 829-839, 2009.

BARROSO, L. R. Curso de direito constitucional contemporâneo: os conceitos fundamentais e a construção do novo modelo. São Paulo: Saraiva, 2009.

BARROSO, L. R. Da falta de efetividade à judicialização excessiva: direito à saúde, fornecimento gratuito de medicamentos e parâmetros para a atuação judicial. Revista de Direito da Procuradoria Geral do Estado do Rio de Janeiro, Rio de Janeiro, n. 63, 2008. Disponível em:

<https://www.pge.rj.gov.br/comum/code/MostrarArquivo.php?C=MTI2MQ\% ${ }_{2} \mathrm{C} \%{ }_{2} \mathrm{C}>$. Acesso em: 25 nov. 2017.

BERRETA, I. Q.; LACERDA, J. T.; CALVO, M. C. Modelo de avaliação da gestão municipal para o planejamento em saúde. Cad. Saúde Pública, Rio de Janeiro, v. 27, n. 11, p. 2143-2154, nov. 2011.

BRASIL. Presidência da República. Emenda Constitucional no 86, de 17 de março de 2015. Altera os arts. 165, 166 e 198 da Constituição Federal, para tornar obrigatória a execução da programação orçamentária que especifica. Brasília (DF), 2015. Disponível em: <http://www.planalto.gov.br/ccivil_o3/constituicao/emendas/emc/emc86.htm >. Acesso em: 22 nov. 2017.

BRASIL. Presidência da República. Decreto no 7.508, de 28 de junho de 2011. Diário Oficial da União, Brasília (DF), 29 jun. 2011a. Seção 1, p. 1.

BRASIL. Presidência da República. Lei no 12.401, de 28 de abril de 2011 . Altera a Lei no 8.080, de 19 de setembro de 1990, para dispor sobre a assistência terapêutica e a incorporação de tecnologia em saúde no âmbito do Sistema Único de Saúde -

Argum., Vitória, v. 10, n. 1, p. 102-117, jan./abr. 2018. 
SUS. Brasília (DF), 2011. Disponível em: <http://www.planalto.gov.br/ccivil_03/_atozo112014/2011/lei/l12401.htm >. Acesso em: 21 nov. 2017.

BRASIL. Ministério da Saúde. Portaria no 3.916, de 30 de outubro de 1998. Aprovar a Política Nacional de Medicamentos. Brasília (DF), 1998, Disponível em:

<http://bvsms.saude.gov.br/bvs/saudelegis/gm/1998/prt3916_30_10_1998.html >. Acesso em: 23 nov. 2017.

BRASIL. Presidência da República. Lei no 8.080 de 19 de Setembro de 1990. Dispõe sobre as condições para a promoção, proteção e recuperação da saúde, a organização e o funcionamento dos serviços correspondentes e dá outras providências. Diário Oficial da União, Brasília (DF), 20 set. 1990. Seção I, p. 18055.

BRASIL. Constituição da República Federativa do Brasil de 1988. Diário Oficial [da] República Federativa do Brasil, Brasília (DF), 2 out. de 1988.

CONSELHO NACIONAL DE JUSTIÇA (BRASIL). Justiça em números 2017: ano-base 2016. Brasília (DF), 2017. Disponível em:

<http://www.cnj.jus.br/files/conteudo/arquivo/2017/12/b6oa659e5d5cb79337945c1dd137496c .pdf>. Acesso em: 22 nov. 2017.

CONSELHO NACIONAL DE JUSTIÇA (BRASIL). Recomendação no $\mathbf{3 1}$, de 30 de março de 2010. Recomenda aos Tribunais a adoção de medidas visando a melhor subsidiar os magistrados e demais operadores do direito, para assegurar maior eficiência na solução das demandas judiciais envolvendo a assistência à saúde. Disponível em: <http://www.cnj.jus.br///images/atos_normativos/recomendacao/recomendacao_31_300320 10_22102012173049.pdf >. Acesso em: 30 nov. 2017.

CONSELHO NACIONAL DE JUSTIÇA (BRASIL). Portaria no 65o, de 20 de novembro de 2009. Cria grupo de trabalho para estudo e proposta de medidas concretas e normativas para as demandas judiciais envolvendo a assistência à saúde. Brasília (DF), 2009. Disponível em: <http://www.cnj.jus.br/busca-atos-adm?documento=496>. Acesso em: 25 nov. 2017

CONSELHO NACIONAL DE SAÚDE (BRASIL). Resolução CNS no 338 de o6 de maio de 2004. Aprova a Política Nacional de Assistência Farmacêutica. Diário Oficial da União, Brasília (DF), 20 maio 2004. Seção I, p. 52. Disponível em:

<http://bvsms.saude.gov.br/bvs/saudelegis/cns/2004/res0338_06_05_2004.html>. Acesso em: 30 nov. 2017.

CANOTILHO, J. J. G. Direito Constitucional e Teoria da Constituição. 7. ed. Coimbra: Almedina, 2003.

CRUZ, M. F. R. O dever do Estado na efetivação do direito à saúde: os papéis dos poderes Executivo, Legislativo e Judiciário. 2014. 265 f. Dissertação (Mestrado de Serviços de Saúde Pública)-Faculdade de Saúde Pública da Universidade de São Paulo, São Paulo, 2014. 
Disponível em: <http://www.teses.usp.br/teses/disponiveis/6/6135/tde-17102014-101022/ptbr.php>. Acesso em: 14 set. 2017. Doi: <10.11606/D.6.2014.tde-17102014-101022>.

DRESCH, Renato Luís. Judicialização da saúde no Brasil: regulação, avanços e perspectivas. Belo Horizonte: Comitê Executivo Estadual da Saúde de Minas Gerais, 15 fev. 2016. Disponível em: <http://www.comitesaudemg.com.br/www/judicializacao-da-saudeno-brasil-regulacao-avancos-e-perspectivas-15-02-16>. Acesso em: 17 fev. 2018.

FERRAZ, O. L. M.; WANG, D. W. L. As Duas Portas do SUS. Folha de São Paulo, São Paulo, 19 jun. 2014. Opinião. Disponível em:

<http://www1.folha.uol.com.br/opiniao/2014/o6/1472761-octavio-ferraz-e-daniel-wang-asduas-portas-do-sus.shtml>. Acesso em: 17 set. 2017.

FERREIRA FILHO, M. G. Aspectos do Direito Constitucional Contemporâneo. São Paulo: Saraiva, 2003.

GIOVANELLA, Ligia. et al. Saúde nas fronteiras: acesso e demandas de estrangeiros e brasileiros não residentes ao SUS nas cidades de fronteira com países do MERCOSUL na perspectiva dos secretários municipais de saúde. Cad. Saúde Pública, Rio de Janeiro, v. 23, suppl.2, p. S251-S266, 2007.

MACHADO, M. A. A. et al. Judicialização do acesso a medicamentos no estado de Minas Gerais, Brasil. Rev. Saúde Pública, São Paulo, v. 45, n. 3, p. 590-598, 2011.

MAPELLI JÚNIOR, R. Palestra no Debate em São Paulo sobre a Criação do NATs (Núcleo de

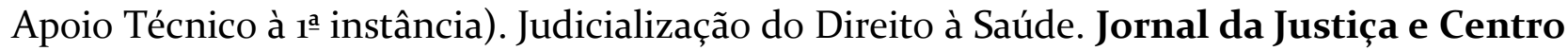
Cochrane do Brasil, São Paulo, p. 28-34, 2012.

MATTOS, K. D. G; SOUZA, G. A. Ativismo Judicial e Políticas Públicas de Saúde: O Impacto da Tutela Jurisdicional de Medicamentos no SUS. In: SIQUEIRA, D. P.; ALVES, F. B. (Orgs.). Políticas públicas da previsibilidade a obrigatoriedade: uma análise sob o prisma do estado social de direitos. Birigui: Boreal, 2011. p. 239-257.

MENDES, G. F. Audiência pública no 4: abertura. Brasília (DF): Supremo Tribunal Federal, 28 abr. 2009. Disponível em:

<http://www.stf.jus.br/arquivo/cms/processoAudienciaPublicaSaude/anexo/Abertura.pdf>. Acesso em: 20 nov. 2017.

NOGUEIRA, V. M. R; PIRES, D. E. P. Direito à saúde: um convite à reflexão. Cad. Saúde Pública, Rio de janeiro, v. 20, n. 3, p. 753-76o, 2004.

NUNES, L. G. A judicialização da saúde no Brasil: Tentativas para reduzir (conter) o fenômeno. Revista da CAAP, Belo Horizonte, n. 2, p. 313-337. jul./dez. 2009.

RIBAS, L. M. et al. Direito ao estrangeiro ao sistema único de saúde: um olhar nas fronteiras de Mato Grosso do Sul. Campo Grande: UFMS, 2013. 
SANT'ANA, J. M. B. et al. Essencialidade e assistência farmacêutica: considerações sobre o acesso a medicamentos mediante ações judiciais no Brasil. Rev Panam Salud Publica, Washington (D.C.), v. 29, n. 2, p. 134-144, 2011.

SARLET, I. W. A eficácia dos direitos fundamentais. 2. ed. Porto Alegre: Livraria do Advogado, 2001.

SILVA, J. A. da. Aplicabilidade das normas constitucionais. 7. ed. São Paulo: Malheiros, 2007.

SILVA, J. A. da. Curso de direito constitucional positivo. 32. ed. rev. e atual. São Paulo: Malheiros, 2009.

STRECK, L. L. A permanência do caráter compromissório (e dirigente) da Constituição Brasileira e o papel da jurisdição constitucional: uma abordagem à luz da hermenêutica filosófica. Revista do Instituto de Pesquisas e Estudos: Divisão Jurídica, Instituição Toledo de Ensino de Bauru, Bauru, n. 39, p. 1-623, 2004.

TAMAKI, E. M.; TANAKA, O. Y. O papel da avaliação para a tomada de decisão na gestão de serviços de saúde. Ciência e Saúde Coletiva, Rio de janeiro, v. 17, n. 4, p. 821-828, 2012.

Disponível em: <http://www.scielo.br/scielo.php?pid=S1413-

$81232012000400002 \&$ script=sci_abstract\&tlng=pt $>$. Acesso em: 28 nov. 2017.

TERRAZAZ, F.. Novos elementos no cenário da judicialização da saúde: análise das decisões dos tribunais superiores. In: SANTOS, L.; TERRAZAS, F. (Org.). Judicialização da saúde no Brasil. Campinas: Saberes, 2014.

TRAVASSOS, D. V. Judicialização da Saúde e Sistema Único de saúde: estudo de Casos de Três Tribunais Brasileiros. 2012. 132 f. Dissertação (Mestrado de Odontologia)-Programa de Pós-Graduação da Faculdade de Odontologia Universidade Federal de Minas Gerais, Belo Horizonte, 2012.

TRAVASSOS, D. V. et al. Judicialização da Saúde: um estudo de caso de três tribunais brasileiros. Ciênc. saúde coletiva, Rio de Janeiro, v. 18, n. 11, p. 3419-3429, Nov. 2013. Disponível em: <http://www.scielo.br/pdf/csc/v18n11/31.pdf>. Acesso em: 24 nov. 2017.

TRIBUNAL DE JUSTIÇA (MATO GROSSO DO SUL). Comitê Estadual de Saúde/Núcelo de apoio Técnico - NAT. Campo Grande, [2017]. Disponível em:

<https://www.tjms.jus.br/nat/>. Acesso em: 29 nov. 2017.

VIANA, A. L. D.; DAL POZ, M. R. A reforma do sistema de saúde no Brasil e o Programa de Saúde da Família. Physis, v. 15, suppl., p. 225-264, 2005. Disponível em:

<http://dx.doi.org/10.159o/So103-73312005000300011>. Acesso em: 29 nov. 2017.

VICENTINI, S. C. Comunicação no Programa de Saúde da Família: a percepção de equipes técnicas multiprofissionais no Município do Rio de Janeiro. 2007. 123 f. Tese (Mestrado 
Profissional em Saúde da Família)-Pós-Gradação da Universidade Estácio de Sá, Rio de Janeiro, 2007.

VIEIRA, F. S.; ZUCCHI, P. Distorções causadas pelas ações judiciais à política de medicamentos no Brasil. Revista de Saúde Pública, São Paulo, v. 41, n. 2, p. 214-22, 2007.

WANG, D.; FERRAZ, O. Reaching out to the needy? Access to justice and public attorneys' role in right to health litigation in the city of Sao Paulo. SUR International Journal on Human Rights, São Paulo, v. 10, n. 18, p. 158-179, Jun. 2013.

WORLD HEALTH ORGANIZATION. The use of essential drugs: seventh report of the WHO Expert Committee: (including the revised Model List Essential Drugs). Geneva, 1997. (WHO Technical Report Series 867).

Ivan Corrêa LEITE. Trabalhou na concepção, delineamento, redação e aprovação da versão do artigo. Mestre em Direito Negocial pela Universidade Estadual de Londrina (UEL, Londrina, Brasil). Professor do Curso de Graduação da Faculdade de Direito da Universidade Federal de Mato Grosso do Sul.

Paulo Roberto Haidamus de Oliveira BASTOS. Trabalhou na concepção, delineamento, redação e aprovação da versão do artigo.

Doutor e Mestre em Educação pela Pontifícia Universidade Católica de São Paulo. (PUCSP, São Paulo, Brasil). Pesquisador Sênior do Programa de Pós-Graduação em Saúde e Desenvolvimento na Região Centro-Oeste da Universidade Federal de Mato Grosso do Sul. 
Argum., Vitória, v. 10, n. 1, p. 102-117, jan./abr. 2018. 